\title{
PONZIO, A. La Rivoluzione Bachtiniana. IL PENSIERO DI BACHTIN E L'IDEOLOGIA CONTEMPORÂNEA. Bari: LeVANTE EdITORI, 1997.357 P.
}

Assunção Cristóvão*

\section{Resumo}

Esta resenha do livro La Rivoluzione Bachtiniana. Il Pensiero di Bachtin e L'Ideologia Contemporanea justifica-se em função da extrema atualidade da obra, que acaba de ser traduzida para o português. Atualidade também revelada por Ponzio sobre a obra do russo Mikhail Bakhtin, que no início do século XX desenvolvia estudos literários e filosóficos que hoje abrem um leque de análise das várias áreas do conhecimento, inclusive no plano ideológico. A obra é um apanhado geral da obra bakhtiniana, sob o viés do filósofo Augusto Ponzio.

Palavras-chave: Mikhail Bakhtin; Filosofia da linguagem; Alteridade; Ideologia.

No início da década de 90, o Muro de Berlin acabava de ser derrubado, prenunciando uma era difícil de ser compreendida por tantos quantos assistiram e/ ou vivenciaram os movimentos estudantis e a efervescência ideológica da década de 60. Passou a dominar a lógica do capital e da chamada globalização. O filósofo Augusto Ponzio, que já havia sido precursor ao publicar, em 1980, a primeira monografia no Ocidente sobre Mikhail Bakhtin, escreveria em 1990 A Revolução Bakhtiniana - O Pensamento de Bakhtin e a Ideologia Contemporânea, publicado em 1997, em que traria para o plano ideológico o pensamento do filósofo russo, produzido tantos anos antes, mas que, sob o olhar de Ponzio, era importante para explicar o novo enquadramento político e social.

Quase 20 anos após ser escrito, o livro continua atual, tanto quanto o aparato teórico utilizado por Ponzio para explicar a nova ordem mundial e aspectos gerais da obra de Bakhtin, de uma forma polêmica, porém original e instigante. Tão interessante para os estudos da Análise do Discurso que o livro foi traduzido em 2008 para o português (A Revolução Bakhtiniana: o Pensamento de Bakhtin e a

*Doutoranda do Programa de Pós-Graduação em Linguística e Língua Portuguesa, Unesp, Araraquara, Brasil, sob orientação da Prof. Dra. Renata Marchezan. sumpy@uol.com.br. 
Ideologia Contemporânea. Coord. de Trad. Valdemir Miotello. Apresentação João Wanderley Geraldi. Introdução e posfácio à edição brasileira Augusto Ponzio. São Paulo: Contexto, 2008, 334 p.). Esta resenha foi feita a partir da obra italiana, durante estágio de doutoramento da autora na Itália, junto à Universitá di Bologna, pouco antes da publicação da tradução no Brasil.

Quem lê pela primeira vez A Revolução Bakhtiniana pode achar que a obra foi escrita somente após a vitória de Silvio Berlusconi e seu partido Popolo della Libertà nas últimas eleições italianas. A oposição identidade $\mathrm{x}$ alteridade utilizada por Ponzio para explicar a nova configuração política e social depois da unificação dos países da União Européia (UE) é eficaz para aclarar tanto a realidade da década de 90 quanto a nova conjuntura criada a partir de 2008, em que foram reforçadas aquelas então incipientes tendências de identidade e desenvolvimento, e que não poderiam ser mais bem exemplificadas do que com a vitória, nas urnas, de Berlusconi que, entre outras bandeiras, utilizou como plataforma eleitoral a ideia de que os imigrantes traziam para a Itália violência e desemprego.

Essa análise, brilhantemente sustentada pelas teorias bakhtinianas, está presente principalmente no primeiro capítulo, denominado Alteridade Bakhtiniana. Nele, Ponzio fala sobre a identidade dos países que formam a UE, identidade como antônimo de alteridade e como justificativa para o desenvolvimento capitalista e para a morte do comunismo.

O autor mostra o quanto, na lógica bakhtiniana, a ideologia dominante contém de identidade, em qualquer campo que se analise. E o quanto essa lógica trabalha a favor da mistificação do homem, que só poderá ser encontrado, em sua verdadeira essência - uma essência inovativa e criativa - no encontro com o outro. Essa noção só pode ser compreendida com o abandono de ideias pré-concebidas em geral aceitas no mundo capitalista, como a de que conceitos como desenvolvimento, identidade cultural e linguística, e outras que comportam a ideia de identidade, têm como finalidade intrínseca favorecer o homem no seu sentido mais amplo.

Ponzio relata que, até o seu último texto, de 1974, Per una Metodologia delle Scienze Umane, Bakhtin não deixou de se questionar sobre o sentido do homem, ainda que aparentemente sua preocupação central fosse a literatura. Para o filósofo italiano, nenhum desenvolvimento, seja de uma comunidade ou de uma nação, pode acontecer em detrimento do sentido último do ser humano, e o conceito que se contrapõe a essa tendência de uniformização, identidade, unificação, é o de alteridade.

Nos capítulos centrais do livro, Ponzio aborda a obra do autor russo e seus "diálogos" com pensadores de seu tempo. O capítulo II, denominado Filosofia Moral e Filosofia da Literatura, cita duas obras de Bakhtin que, para Ponzio, são fundamentais para entender a obra do autor russo: Por uma Filosofia da Ação 
Responsável e $O$ Autor e o Herói. Nelas estaria contida a verdadeira revolução bakhtiniana. São textos que tratam da vida e da arte, ou cultura, e mostram a distinção entre os dois termos, ou o momento exato em que vida se transforma em cultura, quando se determina teoricamente o sentido de um ato significativo, único.

Somente na literatura Bakhtin encontraria um exemplo da arquitetura proposta pela sua filosofia moral. Para Ponzio, o texto literário instaura uma ligação que permite a manutenção da alteridade do centro de valores dessa arquitetura (p. 38).

Mas a palavra teria ainda outra característica derivada dessa alteridade. Como afirma Ponzio (p. 65), "a palavra se dá como dialógica, interiormente dialógica, vale dizer como dialética, intertextual. Ela é irredutível à dialética monológica, que é uma pseudodialética. A lógica dialética é uma dia-lógica".

O capítulo IV, Bakhtin e Vigotsky, é dedicado a este autor que, segundo Ponzio, tem a mesma abordagem cultural do Círculo de Bakhtin e em comum o mesmo viés marxista, em campos como a Psicologia, a Filosofia da Linguagem, a Literatura e a Semiótica. Ponzio percebe em ambos igual tratamento em temas como a relação entre o individual e o social, estrutura e superestrutura, consciência e ideologia social, signo e ideologia, entre individuale psicologia social.

As relações do Círculo com a psicoanálise são tratadas com mais vagar no capítulo V, A Matéria Linguístico-ideológica do Inconsciente. Ponzio relata as restrições e as aproximações de Voloshinov, Medvedev e Bakhtin às teorias de Freud e a sua utilização pelo Círculo, junto com aquelas de Marx e Saussure.

No capítulo VI, Signo e Sentido em Bakhtin, Ponzio reafirma que vê como linha condutora em toda a obra de Bakhtin "o problema do sentido" e de sua individualização e diferenciação nos confrontos do "significado".

O capítulo VII, A Manipulação da Palavra do Outro sob a Forma de Discurso Reportado é dedicado ao discurso do outro presente no nosso discurso, não apenas o discurso reportado, citado, mas qualquer discurso que traga em si o discurso do outro.

Sob o título Signo e Ideologia, Ponzio inicia o capítulo VIII dizendo que, para Bakhtin, a característica peculiar do signo é a sua ideologicidade. Adiferença das noções do termo "ideologia" entre Marx e Bakhtin tambémé lembrada por Ponzio neste capítulo. $\mathrm{O}$ autor alerta para que esse termo, em Bakhtin, não carrega identificação, por exemplo, com "falsa consciência" ou "pensamento distorcido".

A seguir, Ponzio irá relacionar a semiótica Peirciana aos estudos de Bakhtin, no capítulo IX, intitulado Bakhtin e Peirce: Signo, Interpretação e Compreensão.

No capítulo X, Bakhtine Propp, o autor ressalta os traços comuns entre os dois autores no que tange aos seus estudos sobre a cultura popular.

O curto capítulo XI, Diálogo e Dialética, reafirma o caráter de "recomeçar 
sempre de novo" atribuído por Todorov aos estudos bakhtinianos. Um caráter que Bakhtin estenderia à sua noção de texto, no sentido de possuir "uma compreensão dialógica, uma dialética intertextual", no dizer de Ponzio.

A Relação de Alteridade em Bakhtin, Blanchot, Lévinas é o título do capítulo XII da obra, que os considera três filósofos da alteridade, da dissemetria (p. 233).

No capítulo seguinte, O Humanismo da Alteridade em Bakhtin e Lévinas, Ponzio mostra que o que verdadeiramente uniu os dois autores foi "a comum individuação da alteridade na esfera mesma do "eu". "Em Bakhtin e Lévinas, a alteridade é descoberta no interno do sujeito, no eu, o qual é ele mesmo diálogo, relação eu/outro" (p. 258).

Intitulado Crítica da Razão Dialógica, o XV capítulo mostra que o fracasso da razão dialética, tanto na sua fase hegeliana quanto na sartriana, se deve à separação entre "dialética" e "dialógica". Para Ponzio, somente uma crítica da razão dialética poderá permitir a renovação e a recuperação da dialética frente à crise das grandes ideologias e "das sempre crescentes formas de individualismo na vida social" (p. 297).

Ponzio retoma, então, a análise iniciada no capítulo I, e a desenvolve dizendo acreditar que essa tendência estrutural está a caminho da universalização como "o único processo de Produção, Mercado e Consumo". E, para mostrar as consequências negativas de tal processo, volta a citar a unificação européia.

Neste último capítulo (há ainda um apêndice de Susan Petrilli chamado Bakhtin na Itália nos Últimos 15 anos (1980-1995), recuperando tudo o que foi produzido e/ou publicado sobre Bakhtin na Itália no período), Ponzio se detém na questão da alteridade, fechando o ciclo iniciado no capítulo I e que pode ser resumido nestes dois parágrafos da página 304:

A nossa Razão, incluindo as razões da guerra, seja como último recurso, pelo qual ela pode resultar legítima, justa, legal, a nossa Razão, incluindo as razões das eliminações - da marginalização e segregação ao aniquilamento - do outro, a nossa Razão que permite haver a razão do outro, é a Razão da Identidade. A sua lógica da identidade, afirmada pela aproximação ou segregação ou eliminação da alteridade, permite a construção das abstrações concretas sobre as quais ela se rege, entre as quais aquela do Indivíduo, que deve em primeiro lugar sacrificar a própria alteridade a si mesmo.

A crítica a tal Razão requer um ponto de vista outro, pelo qual é necessário preliminarmente o reconhecimento do outro, ou melhor, o reconhecimento da inevitabilidade, da imposição, da 
obrigatoriedade do reconhecimento do outro. Reconhecimento do outro não como concessão, livre decisão do Indivíduo, do Sujeito, do Mesmo, mas como necessidade imposta da alienação, da perda de sentido, da situação do homem lobo do próprio homem.

Enfim, além dos óbvios méritos da obra, escrita por um filósofo da estatura de Augusto Ponzio, o livro nos permite retomar e esclarecer importantes conceitos de Bakhtin. Mais do que isso, Ponzio dialoga com esses conceitos a partir de um contexto novo, moderno, da Europa pós-União Européia, do sujeito emaranhando na complexa teia da nova ordem política e econômica, uma ordem baseada na lógica da identidade e não da alteridade.

\section{Agradecimentos}

Expressamos aqui nosso agradecimento à Coordenadoria de Aperfeiçoamento de Pessoal de Nível Superior (Capes), que, por meio da concessão de uma bolsa de doutoramento (PDEE), possibilitou estágio de pesquisa na Itália, sob a supervisão do Prof. Dr. Federico Pellizzi (Università di Bologna).

\section{Title: PONZio, A. La Rivoluzione Bachtiniana. Il Pensiero di Bachtin E

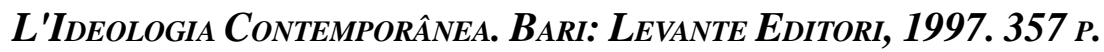

\section{ABSTRACT}

This book review of The Bakhtinian revolution: Mikhail Bakhtin's thought and the contemporary ideology ("La rivoluzione bachtiniana. Il pensiero di Bachtin e l'ideologia contemporanea") by Augusto Ponzio is justified by the modern relevance of this work, which has just been translated into Portuguese. This relevance is also revealed by Ponzio in explaining the work of the Russian Mikhail Bakhtin, who, at the beginning of the twentieth century, wrote literary and philosophical studies that are now opening up a range of analysis in several areas of knowledge, including the ideological dimension. The book is an overview of Bakhtin's work, from the perspective of the philosopher Augusto Ponzio.

KEYWORDs: Mikhail Bakhtin; Philosophy of language, Otherness; Ideology. 